\title{
n-Parties Contract Based Transportation Problem and Its Solution
}

\author{
Jignasha G. Patel*, Jayesh M. Dhodiya** \\ *(General Department, Shri K. J. Polytechnic, Bholav, Bharuch, Gujarat, India \\ ** (Department of Applied Mathematics and Humanities, S. V. National Institute of Technology, Surat, Gujarat, \\ India
}

\begin{abstract}
In transportation problem, for transporting a product from supply origins to demand destinations, a company declared the tender, once a company gain total transportation cost. Numbers of Transportation Company are interested in this tender. Out of them, some companies are not able to fulfill the requirements of the tender so such companies are combining to gather and jointly apply in tendering to get the assignment. All the companies which are jointly applying, having different power. So it is necessary for all companies to decide some strategies according to their cost, profit and units of supply before applying in such tendering procedure so that all companies will get maximum benefit. In this paper, we developed the model and solve such type of transportation problems with proper illustration by using LINGO package and Nash Bargaining model based approach when more than two companies are jointly applied in the tendering process and from that we find non integer and integer solutions respectively.
\end{abstract}

Keywords - Transportation Problem, Multi-Objective Transportation Problem, Bargaining, Profit Matrices, Strategy

\section{INTRODUCTION}

The simplest transportation model has been developed by F. L. Hitchcock in 1941. Transportation problem have been extensively studied in operation research where distribution of product from several origins to several warehouses is a central issue. To satisfy the warehouse requirements within the operating production capacity constraints at the minimum possible cost is the purpose in a transportation problem. Transportation problem is one of the elementary problems which are used to minimize the transportation cost with the help of numbers of sources and numbers of destinations while satisfying the deliver limit and demand requirement [6].

In real life situations, all the transportation problems are not single objective. The real world transportation problem can be formulated as a multiobjective transportation problem because the convolution of the social and profitable environment requires the unambiguous consideration of criteria other than cost [2]. In multi-objective transportation problem constraints are of inequality type and all the objectives are non-commensurable and conflict with each other. On the foundation of the demands of sustainable development, must consider many features, such as protecting natural resources, pollution control, cost saving, energy saving, time saving and so on [9]. The real life transportation problems are modeled with multi-objectives which are measured in different scales and at the same time in conflict Transportation problem have been extensively studied in operation research where distribution of product from several origins to several warehouses is a central issue [2]. To satisfy the warehouse requirements within the operating production capacity constraints at the minimum possible cost, time, product defectiveness etc. are the purpose in a transportation problem. To minimize cost, time, product defectiveness etc. and improving service, transportation problem plays an important role in industry, communication network, planning, scheduling transportation and supply chain management etc. [10].

In the real world, for transporting a product, some companies are not able to fulfill the requirements of the tender so such companies having different power jointly apply in tendering to get the assignment. Thus, it is essential for all companies to decide some strategies according to their power so that all the companies will get maximum benefit.

Nash (1950) affords axiomatic characterization of a cooperative bargaining solution after that in 1953 provided the non-cooperative justification of his solution concept by using his own demand game. Roth and Murnighan (1982) compare bargaining under complete and incomplete information and shows that how bargaining outcomes are significantly different when the level of information changes. Rubinstein and Wolinsky 
(1985) incorporate an outside option in an alternating-offer bargaining process. Binmore, Rubinstein and Wolinsky (1986) showed that as the time between alternating offers by players bargaining game tends to zero, the unique sub game perfect equilibrium outcome corresponds to one of the asymmetric Nash solutions, depending on the relative discount factors of the players. Herrero (1989) considered the axioms that in general result in a multi-valued solution for non-convex bargaining problems. She showed that the bargaining solution satisfying her axioms can be essentially characterized by an equal distance property [8]. Howard (1992) proposed multiple-stage non-cooperative foundation for the Nash solution, which was later significantly simplified by Rubinstein, Safra and Thomson (1992). Chatterjee and Lee (1993) study the situation with incomplete information about the outside option. Among them, Conley and Wilkie.s (1996) considered a single-valued extension of the Nash bargaining solution that involves randomization. Zhou (1997) considered an extension of the Nash bargaining theory and his results imply that the axiomatic characterization of the asymmetric Nash bargaining solution has a high degree of generality. Cunyat (1998) re-examined the robustness of the Outside Option Principle based on Rubinstein's bargaining model with complete information [1]. P. Heiskanen, H. Ehtamo, and R. P. Hmlinen (2001) developed a constraint proposal method for computing Pareto solutions in multi-party negotiations. Pu Huang and Katia Sycara (2002) proposed a computational model for online agent negotiation. Braun and Gautschi (2004) show predictions of exchange patterns become feasible if the current model is extended to the analysis of non-robust structures. Norman Braun, Thomas Gautschi (2006) focus on simple exchange networks and present a formal model for predicting profit splits from such structures also they combine the generalized Nash bargaining solution from game theory with the assumption that both relational features and network positions affect exchange outcomes [11]. Ujjwal Kumar (2007) focus on the solution of web based bargaining using genetic algorithm [12]. Laruelle and Valenciano (2008), Britz, Herings and Predtetchinski (2010) provided various non-cooperative multilateral bargaining game models provided non- cooperative support to the nperson a symmetric Nash solutions. In these games, in the first period of an infinitely repeated bargaining game, one out of the $n$ players is recognized as the proposer. If a proposal is rejected, negotiations break down. Kultti and Vartiainen (2010) generalize Binmore et al. and they show that differentiability of the payoff set on Pareto frontier is essential for the convergence result if there are at least three players [11]. P. Judson Kenney (2013) proposed supply chain bargaining theory [10]. Y.H. Gu (2013) develops a bargaining mechanism for a two-party business cooperation model with integer-valued profit functions on 2-partition of a beneficial object consisting of finite inseparable parts [13]. Joe McCool and Isaac Davis (2016) a score-based method for solving bargaining problems that offer more information and tools than traditional scorebased bargaining solutions.

In many real world observable facts, it is complicated to convert all situations into mathematical form whenever many companies jointly apply for transportation assignments. After getting transportation assignment, a bargaining situation develops between them. This type of situation is difficult to convert into mathematical form. In most of such cases, if more than two parties or companies are jointly applying to get an assignment, all companies decide their strategies according to cost and profit for transporting a product.

In this paper, we developed a mathematical formulation of n-parties contract based transportation problem and find its non integer solution by classical method while its integer solution by using Nash bargaining theory. The rest of the paper is organized as follows:

\section{FORMULATION OF TRANSPORTATION PROBLEM}

2.1 Transportation Problem with Single Objective The general transportation problem mathematically stated as follows:

Minimize (total cost) $\mathrm{Z}=\sum_{i=1}^{m} \sum_{j=1}^{n} c_{i j} x_{i j}$

Subject to the constraints

$\sum_{j=1}^{n} x_{i j}=a_{i}, \quad i=1,2, \ldots . ., m$ (Supply constraints)

$\sum_{i=1}^{m} x_{i j}=b_{j}, j=1,2, \ldots ., n$ (Demand constraints)

And $x_{i j} \geq 0$ for $i$ and $j$.

Where, $x_{i j}$ represents thenumber of units shipped per route from source $i(i=1,2,3)$ to destination $j(j=1$, $2,3,4) . m$ sources of supply, $S_{1}, S_{2}, \ldots ., S_{m}$ having $a_{i}$ $(i=1,2, \ldots ., m)$ units of supply respectively, to be 


\begin{tabular}{|c|c|c|c|c|c|}
\hline & $D_{1}$ & $D_{2}$ & $\cdots$ & $D_{n}$ & Supply $a_{i}$ \\
\hline$S_{1}$ & $c_{11}$ & $c_{12}$ & $\cdots$ & $c_{1 n}$ & $a_{1}$ \\
\hline$x_{11}$ & $x_{12}$ & & $x_{1 n}$ & \\
\hline$S_{2}$ & $c_{21}$ & $c_{22}$ & $\cdots$ & $c_{2 n}$ & $a_{2}$ \\
\hline$\vdots$ & $x_{21}$ & $x_{m 2}$ & & $x_{2 n}$ & \\
\hline$S_{m}$ & $c_{m 1}$ & $c_{m 2}$ & $\cdots$ & $c_{m n 2}$ & $a_{m}$ \\
\hline $\begin{array}{c}\text { Demand } \\
b_{j}\end{array}$ & $x_{m,}$ & $x_{m n}$ & & $x_{m n}$ & \\
\hline
\end{tabular}

Table 1 General Transportation Table

transported among $n$ destinations, $D_{1}, D_{2}, \ldots \ldots, D_{n}$ with $b_{j} \quad(j=1,2, \ldots, n)$ units of requirement respectively. $c_{i j}$ be the cost of shipping one unit of the commodity from sources $i$ to destination $j$ for each route.

The general optimal solution by using modified method [6] can be represented in table form as above: The Table-1 represents general optimal solution of transportation problem is as above:

\subsection{Transportation Problem with Multiple Objective}

In multi-objective transportation problem, a product is to be transported from $m$ sources to $n$ destinations and their capacities are $a_{1}, a_{2}, \ldots ., a_{m}$ and $b_{1}, b_{2}, \ldots, b_{n}$ respectively. In addition, there is a penalty $c_{i j}$ associated with transporting a unit of product from $i^{\text {th }}$ source to $j^{\text {th }}$ destination. This penalty may be cost or delivery time or safety of delivery or etc. A variable $x_{i j}$ representing the unknown quantity to be shipped from $i^{\text {th }}$ source to $j^{t h}$ destination. A mathematical model of transportation problem with $r$ objectives, $m$ sources and $n$ destinations can be written as:

Minimize $Z_{r}=\sum_{i=1}^{m} \sum_{j=1}^{n} c_{i j}^{r} x_{i j}, r=1,2, \ldots ., k$

Subject to

$\sum_{j=1}^{n} x_{i j}=a_{i}, i=1,2, \ldots ., m$

$\sum_{i=1}^{m} x_{i j}=b_{j}, \quad j=1,2, \ldots ., n$

$x_{i j} \geq 0, \quad \forall i, j$

The subscript on $Z_{r}$ and superscript on $c_{i j}^{r}$ are related to the $r^{\text {th }}$ penalty criterion. Without loss of generality, it may be assumed that $a_{i} \geq 0, b_{j} \geq 0$ $\forall i, j$ and the equilibrium condition $\sum_{i=1}^{m} a_{i}=\sum_{j=1}^{n} b_{j}$ is satisfied [4]. The general table for multi-objective transportation problem is given below [5]:

Table 2: General Multi-objective Transportation Table

\begin{tabular}{|c|c|c|c|c|c|}
\hline $\begin{array}{c}\text { Destinations } \\
\text { Resource } \downarrow\end{array}$ & $B_{1}$ & $B_{2}$ & $\cdots$ & $B_{n}$ & Supply \\
\hline & $c_{11}^{(1)}$ & $c_{12}^{(1)}$ & & $c_{1 n}^{(1)}$ & \\
$A_{1}$ & $c_{11}^{(2)}$ & $c_{12}^{(2)}$ & & $c_{1 n}^{(2)}$ & $a_{1}$ \\
& $\vdots$ & $\vdots$ & $\cdots$ & $\vdots$ & \\
& $c_{11}^{(3)}$ & $c_{12}^{(3)}$ & & $c_{1 n}^{(3)}$ & \\
\hline$\vdots$ & $\cdots$ & $\cdots$ & $\vdots$ & $\cdots$ & $\vdots$ \\
& $c_{m 1}^{(1)}$ & $c_{m 2}^{(1)}$ & & $c_{m n}^{(1)}$ & \\
& $c_{m 1}^{(2)}$ & $c_{m 2}^{(2)}$ & & $c_{m n}^{(2)}$ & \\
$A_{m}$ & $\vdots$ & $\vdots$ & $\cdots$ & $\vdots$ & $a_{m}$ \\
& $c_{m 1}^{(3)}$ & $c_{m 2}^{(3)}$ & & $c_{m n}^{(3)}$ & \\
\hline Demand & $b_{1}$ & $b_{2}$ & $\cdots$ & $b_{n}$ & \\
\hline
\end{tabular}

\section{III. $N$-PARTIES CONTRACT BASED TRANSPORTATION PROBLEM}

A general mathematical model of n-parties contract based transportation problem is formulated as follows.

Let $x_{i j}^{\prime}$ represents thenumber of allocated units shipped per route from source $i(i=1,2,3)$ to destination $j(j=1,2,3,4)$ for all companies which are jointly apply $r \quad(r=1,2, \ldots ., q)$. Let there be $m$ sources of supply, $S_{1}, S_{2}, \ldots ., S_{m}$ having $a_{i}$ $(i=1,2, \ldots, m)$ units of supply respectively, to be transported among $n$ destinations, $D_{1}, D_{2}, \ldots \ldots, D_{n}$ with $b_{j} \quad(j=1,2, \ldots, n)$ units of requirement respectively. Let $X_{r}$ denotes the number of units consider by all companies $r(r=1,2, \ldots \ldots, q)$. Let $c_{i j}$ be the cost of shipping one unit of the commodity from sources $i$ to destination $j$ for each route (Here we only consider the cost $c_{i j}$ at which the number of units $x_{i j}$ are allocated for each party). Let $\mathrm{k}(\mathrm{k}=1,2$, $\ldots, \mathrm{s})$ denotes the number of objectives. Let $P^{(r)}$ represents the profit matrix of each party for transporting units. Let $P^{(r)^{\prime}}$ represents the cost matrix of transporting one unit of the commodity from sources $i$ to destination $j$ for party $\mathrm{r}$ at each route. $\mathrm{C}$ denotes the total transportation cost. Mathematically, this type of situation in general may be stated as follows: 


\section{MODEL 1}

Maximize $Z_{r}=\sum_{i=1}^{m} \sum_{j=1}^{n} P_{i j}^{(r)} x_{i j}^{\prime}$

Where $x_{i j}^{\prime}=\left\{\begin{array}{cc}0 & x_{i j} \notin x \\ x_{i j} & x_{i j} \in x\end{array}\right.$

Where $\mathrm{x}$ is a set of allocated units.

Subject to

$\sum_{r=1}^{q} \sum_{j=1}^{n} x_{i j r}^{\prime}=a_{i}, \quad i=1,2, \ldots ., m$

$\sum_{r=1}^{q} \sum_{i=1}^{m} x_{i j r}^{\prime}=b_{j}, \quad j=1,2, \ldots, n$

$\sum_{j=1}^{n} \sum_{i=1}^{m} x_{i j r}^{\prime} \geq X_{r}, \quad r=1,2, \ldots ., q$

$\sum_{j=1}^{n} \sum_{i=1}^{m} x_{i j r}^{\prime} \leq X_{r}, \quad r=1,2, \ldots ., q$

$\sum_{r=1}^{q} \sum_{i=1}^{m} \sum_{j=1}^{n} c_{i j} x_{i j r}^{\prime}=C$

$x_{i j r}^{\prime} \geq 0, \forall i, j, r$

Where $\quad P^{(r)}=\left[\begin{array}{cccc}P_{11}^{r} & P_{12}^{r} & \cdots & P_{1 n}^{r} \\ P_{21}^{r} & P_{22}^{r} & \cdots & P_{2 n}^{r} \\ \vdots & \vdots & \vdots & \vdots \\ P_{m 1}^{r} & P_{m 2}^{r} & \cdots & P_{m n}^{r}\end{array}\right]$ is the profit

matrix for each party.

The cost matrix from the profit matrix given above

$$
P^{(r)^{\prime}}=\left[\begin{array}{cccc}
P_{11}^{(r)^{\prime}} & P_{12}^{(r)^{\prime}} & \cdots & P_{1 n}^{(r)^{\prime}} \\
P_{21}^{(r)^{\prime}} & P_{22}^{(r)^{\prime}} & \cdots & P_{2 n}^{(r)^{\prime}} \\
\vdots & \vdots & \vdots & \vdots \\
P_{m 1}^{(r)^{\prime}} & P_{m 2}^{(r)^{\prime}} & \cdots & P_{m n}^{(r)^{\prime}}
\end{array}\right]
$$

The solution to such problems is possible by using classical as well as bargaining theory based method. In this paper we utilized classical method as well as bargaining theory [7] to find integer and non integer solutions respectively.

\section{SOLUTION METHODOLOGY}

In real life transportation problem after fix on total transportation cost, a company or government declares tender. Many transportation companies apply in the tendering process to get the tender but some companies are not able to execute the necessity of the tender. So such companies are joining together and apply in the tendering process. After achieving the tender such companies decide some strategies such as deciding minimum and maximum units to be transported from origins to destinations.
To solve such type of problems, the first step to decide profit matrix for all companies to transport units from origins to destinations as

$$
P^{(r)}=\left[\begin{array}{cccc}
P_{11}^{r} & P_{12}^{r} & \cdots & P_{1 n}^{r} \\
P_{21}^{r} & P_{22}^{r} & \cdots & P_{2 n}^{r} \\
\vdots & \vdots & \vdots & \vdots \\
P_{m 1}^{r} & P_{m 2}^{r} & \cdots & P_{m n}^{r}
\end{array}\right]
$$

From the profit matrices gain cost metrics for all companies as

$$
P^{(r)^{\prime}}=\left[\begin{array}{cccc}
P_{11}^{(r)^{\prime}} & P_{12}^{(r)^{\prime}} & \cdots & P_{1 n}^{(r)^{\prime}} \\
P_{21}^{(r)^{\prime}} & P_{22}^{(r)^{\prime}} & \cdots & P_{2 n}^{(r)^{\prime}} \\
\vdots & \vdots & \vdots & \vdots \\
P_{m 1}^{(r)^{\prime}} & P_{m 2}^{(r)^{\prime}} & \cdots & P_{m n}^{(r)^{\prime}}
\end{array}\right]
$$

So the Model 1 become

Minimize $Z_{r}=\sum_{i=1}^{m} \sum_{j=1}^{n} P_{i j}^{(r)^{\prime}} x_{i j}^{\prime}$

Subject to the constrain (1) - (5) and $x_{i j r}^{\prime} \geq 0, \forall i, j, r$.

Companies joining together decide their individual minimum and maximum capacity of units to be transport from sources to destination. Also add the total transportation cost which was decided by a company or government.

Solve the transportation problem using each time only cost matrix of the party and ignoring others. Determine the corresponding values for all parties at each solution derived from the above results of individual party. Then construct a pay-off matrix as in Table 3, with different solutions obtained.

Table 3 Pay off matrix

\begin{tabular}{|c|c|c|c|c|}
\hline & $f_{1}(x)$ & $f_{2}(x)$ & $\cdots$ & $f_{k}(x)$ \\
\hline$x^{1}$ & $f_{1}^{*}\left(x^{1}\right)$ & $f_{2}\left(x^{1}\right)$ & $\cdots$ & $f_{k}\left(x^{1}\right)$ \\
\hline$x^{2}$ & $f_{1}\left(x^{2}\right)$ & $f_{2}^{*}\left(x^{2}\right)$ & $\cdots$ & $f_{k}\left(x^{2}\right)$ \\
\hline$\vdots$ & $\vdots$ & $\vdots$ & $\vdots$ & $\vdots$ \\
\hline$x^{k}$ & $f_{1}\left(x^{k}\right)$ & $f_{2}\left(x^{k}\right)$ & $\cdots$ & $f_{k}^{*}\left(x^{k}\right)$ \\
\hline
\end{tabular}

Find the lower and upper bounds $f_{k}^{L}(x)$ and $f_{k}^{U}(x)(k=1,2,3, \ldots ., k)$, from the pay off matrix as in Table 3 and we obtained the best lower bound lower bound and worst upper bound corresponding to the set of solutions.

In terms of the aspiration levels of each party, the initial fuzzy model stated, as follows:

Find $x_{i j}, i=1,2, \ldots \ldots, m ; j=1,2, \ldots \ldots, n$ so as to satisfy $f^{r} \leq L^{r}$ where $(r=1,2,3, \ldots \ldots, k)$ with the given constraints and non- negativity conditions. 
After that we apply linear membership function and the exponential membership function which is as follows:

$$
\mu_{k}(x)=\left\{\begin{array}{cc}
1 & \text { if } f_{k} \leq f_{k}^{L} \\
1-\frac{f_{k}-f_{k}^{L}}{f_{k}^{U}-f_{k}^{L}}, & \text { if } f_{k}^{L}<f_{k}<f_{k}^{U} \\
0 & \text { if } f_{k} \geq f_{k}^{U}
\end{array}\right.
$$

Maximize $\lambda$

$$
\text { Subject to } \lambda \leq \frac{f_{k}^{U}-f_{k}}{f_{k}^{U}-f_{k}^{L}} \text { for all } \mathrm{k}
$$

And the given constraints, the non-negativity conditions as well as $\lambda \geq 0$, where $\lambda=\min \left\{\mu_{k}(x)\right\}$.

This linear programming problem can further be simplified as Model 2.

Model 2 Maximize $\lambda$

$$
\text { Subject to } f_{k}+\lambda\left(f_{k}^{U}-f_{k}^{L}\right) \leq f_{k}^{U}
$$

With the given constraints, non-negativity restriction and $\lambda \geq 0$.

Using LINGO package all parties obtain their individual cost and profit, according to their requirement of units [3].

Type 2 Exponential Membership Function To solve the Model obtained in Step 3, an exponential membership function $\mu_{k}^{e}\left(f_{k}\right)$ corresponding to $\mathrm{k}^{\text {th }}$ objective function has been defined as

$$
\mu_{k}^{e}(x)=\left\{\begin{array}{cc}
1 & \text { if } f_{k} \leq f_{k}^{L} \\
\frac{e^{-s \psi_{k}(x)}-e^{-s}}{1-e^{-s}} & \text { if } f_{k}^{L}<f_{k}<f_{k}^{U} \\
0 & \text { if } f_{k} \geq f_{k}^{U}
\end{array}\right.
$$

Where $\psi_{k}(x)=\frac{f_{k}-f_{k}^{L}}{f_{k}^{U}-f_{k}^{L}}, k=k=1,2,3, \ldots, K$.

$\mathrm{s}$ is a non-zero parameter prescribed by the decision maker.

If exponential membership function be used, then the problem is modified as model 3.

Model 4 Maximize $\lambda$

Subject to $e^{-s \psi_{k}(x)}-\left(1-e^{-s}\right) \lambda \geq e^{-s}$ for all $\mathrm{k}$

With the given constraints and non-negativity restriction and $\lambda \geq 0[3]$.

\section{DEVELOPED ALGORITHM}

Developed algorithm to solve n-Parties contract based Transportation Problem is as follows:

Input

Profit matrix $P_{r}=\left(P_{1}, P_{2}, \ldots \ldots, P_{k}\right)$

\section{Output}

Solution of MOTP
Compute the efficient solution of MOTP using linear and exponential membership functions.

Solve MOTP

begin

Step 1 Read: Example

while example $=$ MOTP do

for $\mathrm{r}=1$ to $\mathrm{k}$ do

Profit matrix $P_{r}$

end

Step 2 Obtain cost matrix $P_{r}^{\prime}=\left(P_{1}^{\prime}, P_{2}^{\prime}, \ldots \ldots, P_{k}^{\prime}\right)$ from the profit matrix $P_{r}=\left(P_{1}, P_{2}, \ldots \ldots, P_{k}\right)$.
for $\mathrm{r}=1$ to $\mathrm{k}$ do
Cost matrix $P_{r}$
end

Step 3 Solve the transportation problem using each time only one cost matrix and ignoring others. Determine the corresponding values for all parties at each solution derived from the above results of individual party.

for $\mathrm{r}=1$ to $\mathrm{k}$ do

$$
P_{r}^{\prime}=\left[\begin{array}{cccc}
P_{11 r}^{\prime} & P_{11 r}^{\prime} & \cdots & P_{11 r}^{\prime} \\
P_{11 r}^{\prime} & P_{11 r}^{\prime} & \cdots & P_{11 r}^{\prime} \\
\vdots & \vdots & \vdots & \vdots \\
P_{11 r}^{\prime} & P_{11 r}^{\prime} & \cdots & P_{11 r}^{\prime}
\end{array}\right]
$$

end

Step 4 Create the pay-off matrix as in Table 3 from the above solutions and find the upper bound $U^{r}$ and lower bound $L^{r}$ from it.

$$
\text { for } \mathrm{r}=1 \text { to } \mathrm{k} \text { do }
$$$$
U^{r} \text { and } L^{r}
$$

end

Step 5 Develop Model 2, Model 3 and solve them using LINGO package. The solutions obtained are the compromise solutions for each party.

for $\mathrm{k}=1$ to $\mathrm{n}$ do $\max \lambda$

$$
f_{k}+\lambda\left(f_{k}^{U}-f_{k}^{L}\right) \leq f_{k}^{U}
$$

and

$\max \lambda$

$e^{-s \psi_{k}(x)}-\left(1-e^{-s}\right) \lambda \geq e^{-s}$ for all $\mathrm{k}$

Where $\psi_{k}(x)=\frac{f_{k}-f_{k}^{L}}{f_{k}^{U}-f_{k}^{L}}, k=k=1,2,3, \ldots, K$.

Subject to the given constraints and non-negativity restriction and $\lambda \geq 0$

end

\section{DEVELOPED N-PARTIES BARGAINING MODEL}

Numbers of real world problem can be solved using bargaining theory, for example, cyber haggler (Web based bargaining), supply chain, job sequencing etc. $[11,13]$. In this chapter we have also 
developed an integer solution technique by using $n$ parties bargaining model algorithm which gives an efficient solution for all transportation companies when they jointly apply for transportation assignment in the tendering process and the comparison between the solution which can be obtain using Nash Bargaining Model based approach for $n$-Bargainers in transportation and also achieve the solution using LINGO package with some additional constraints.
Suppose $n$-companies with different power jointly apply for tendering and get an assignment. For find bargaining based solution for $n$-Companies, first it is necessary to divide $n$-Companies into all possible pairs of groups of two companies. For example, suppose three companies $[1,2,3]$ are jointly applying then possible pair of groups of two companies are as follows: $[(1,2), 3],[(2,3), 1]$ and $[(1,3), 2]$.

Fig. 1 Possible pairs for three companies

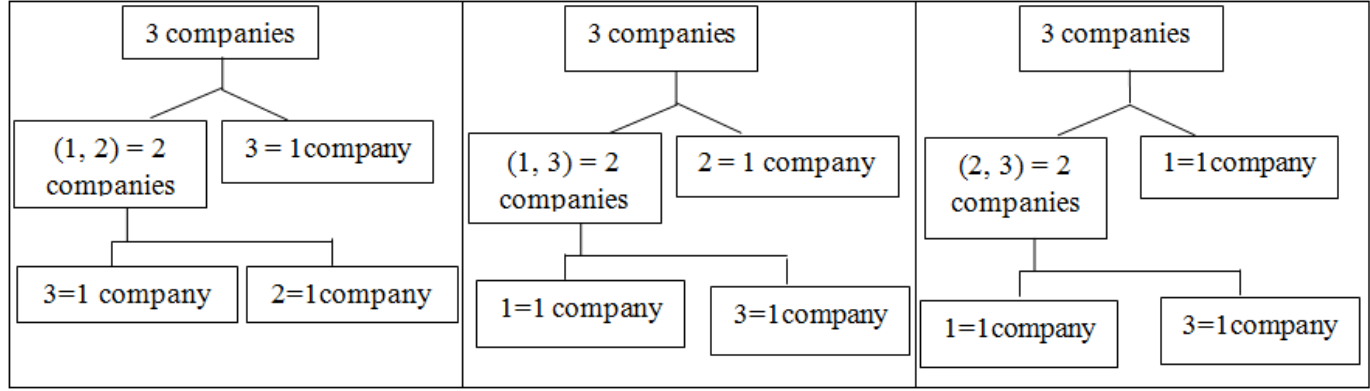

Fig. 2 Possible pair of four Companies

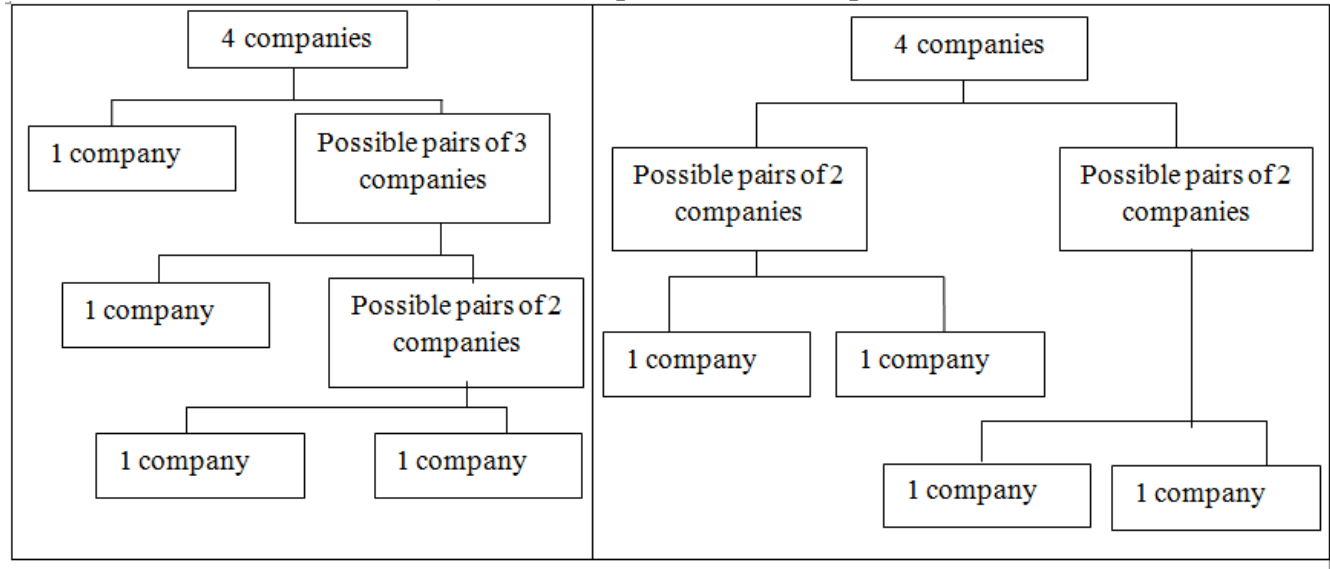

The possible ways to divide n-parties into pairs of groups are as follows:

Possible way-1

Possible way-2

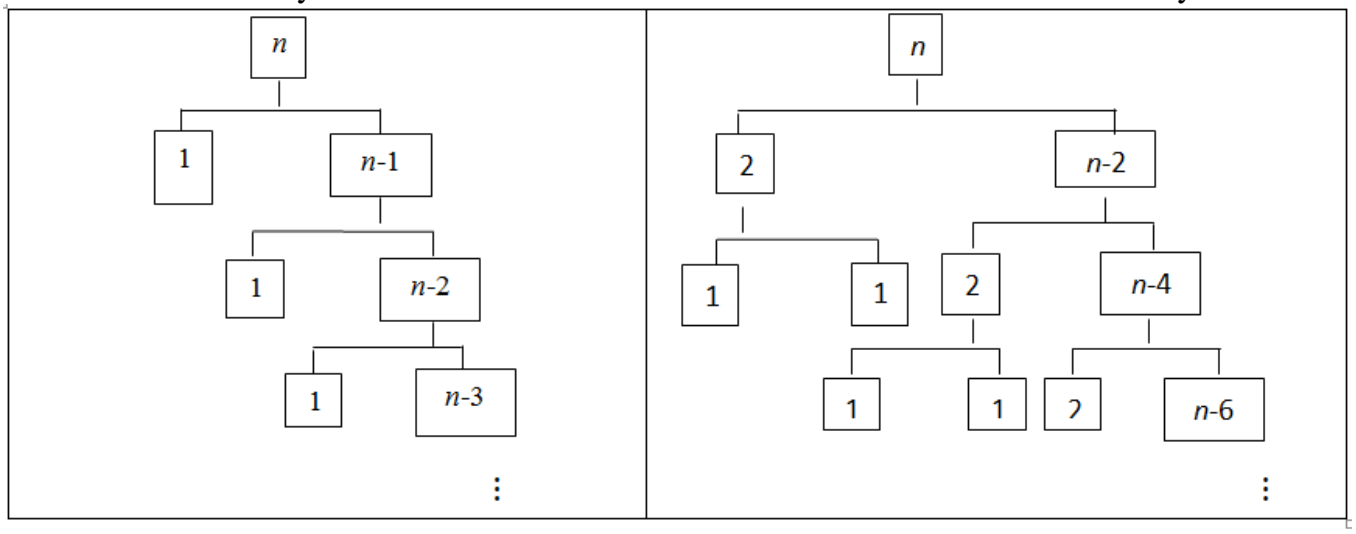

Possible way-3

possible way-k 


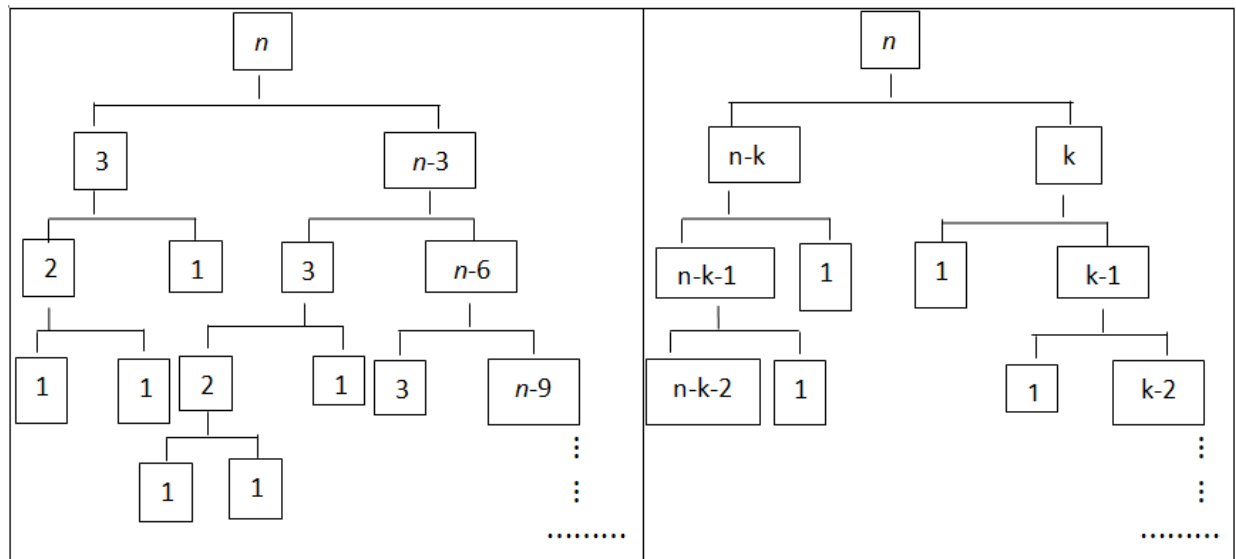

When n-parties convert into all possible pairs of groups for obtaining the maximum profit, all parties bargain with respect to their maximum capacity and threat point. Here, each possible pair of groups has a number of possible allocations of units for jobs and according to their capability, each pair of groups decide strategies for appropriate costs called as utilities. These strategies of cost give all possible strategies of allocated units thereafter the concept of Nash formula (as in [7]) applies to product of utilities for obtaining the maximization points which give an optimal solution for each possible pair of groups, also maximization points will give the best strategies for all possible pairs of groups.

Once pairs of groups achieve their best strategies after that they also divide into possible pairs of subgroups and these subgroups again bargain for appropriate cost with respect to their maximum capacity and threat point for obtain all new possible strategies from each best possible strategy of groups. Once again using the Nash formula for obtains maximization points for an optimal solution. This gives the best strategies for each possible pair of subgroups.

Repeat the above process till each company will obtain their individual utility of cost. Now multiply the utility of each company of groups for obtaining the maximization point. From maximization point of each group, select the group whose maximization point is greatest from all other groups. (Because this maximization point gives an optimal solution for each company according to their maximum capability and threat point).

Hence, using the method of n-parties bargaining model, all companies joining together and apply for an assignment to achieve their efficient profit according to their capability.

\section{DEVELOPED ALGORITHM OF N- PARTIES BARGAINING MODEL USING THE CONCEPT OF NASH BARGAINING THEORY}

Nash solution of bargaining problem is obtained by the following steps when numbers of companies jointly apply for the tendering process:

Input

n- parties $\left(A=B_{1}, B_{2}, \ldots \ldots, B_{m}\right)$

\section{Output}

Solution for each party $B_{1}, B_{2}, \ldots \ldots, B_{m}$ Compute the efficient solution for all parties.

Solve n-parties bargaining model

begin

Step 1 Find all possible pairs of groups (as in above figure) after that find all possible strategies of units (jobs as $J_{1}, J_{2}, \ldots ., J_{k}$ ) for each possible pair of groups according to their minimum and maximum capacity to transport units called as utilities and also find utility product.

Read: all possible pairs of groups

while example $=n$-parties bargaining problem

for $\mathrm{p}=1$ to $\mathrm{k}$ do

$$
J_{p}=\left[J_{p}, J_{k-p}\right]
$$

end

for $\mathrm{n}=1$ to $\mathrm{m}$ do

$$
Z_{n}=A_{m-n} \cdot A_{n}
$$

end

Step 2 Apply the Nash bargaining formula on utility product for finding maximization points which gives optimal solution and best strategies for each possible pairs of groups.

for $\mathrm{n}=1$ to $\mathrm{m}$ do

$$
\max Z_{n}=A_{m-n} \cdot A_{n}
$$

end

Step 3 Find subgroups of all possible pairs of groups afterwards find all new possible strategies for subgroups from best possible strategies of groups.

for $\mathrm{k}=1$ to $\mathrm{s}$ do 


$$
J_{k}=\left[J_{k}, J_{s-k}\right]
$$

end

for $\mathrm{m}=1$ to $\mathrm{q}$ do

$$
Z_{m}=A_{q-m} \cdot A_{m}
$$

end

Step 4 Again applies the Nash bargaining formula on utility product of subgroups for finding maximization points which gives optimal solution and best strategies for each possible pairs of Subgroups. If maximization points for subgroups which are obtained by best strategies of group, are more than, then select the maximization point which is greatest from all other maximization points.

for $\mathrm{m}=1$ to $\mathrm{q}$ do

$$
\max Z_{m}=A_{q-m} \cdot A_{m}
$$

if $\max Z_{m}>1$

read all possible pair of $\max Z_{m}$

select $\max Z_{m}$

end

end

Step 5 Repeat the above process till each company will obtain their individual utility after that find maximization points for each group by multiplying utilities of each company.

Step 6 Select the group whose maximization point is greatest which give an optimal solution to each company.

for $\mathrm{n}=1$ to $\mathrm{m}$ do

\section{end}

$$
A=\max \left[A_{n}\right]
$$

Now, using grey situation decision making theory, Model 2 converts in to the single objective transportation problem and after that for the further solutions apply the same methods and algorithms which are given above.

\section{ILLUSTRATIONS}

8.1 Transportation Problem with Single Objective A company has three production facilities $S_{1}, s_{2}$ and $s_{3}$ with production capacity of 7, 9 and 18 units (in 100s) per week of a product, respectively. These units are to be shipped to four warehouses $D_{1}, D_{2}, D_{3}$ and $D_{4}$ with requirement of 5, 6, 7 and 14 units (in 100's) per week, respectively. Using the Vogel's approximation method, the initial solution with minimum total transportation cost Rs 779. The next Step is to check optimality. Using MODI (Modified Distribution) Method, the optimal solution is shown in Table 4 [6].
Table 4

\begin{tabular}{|c|c|c|c|c|c|}
\hline & $D_{1}$ & $D_{2}$ & $D_{3}$ & $D_{4}$ & Supply \\
\hline$S_{1}$ & 19 & 30 & 50 & 10 & 7 \\
& 5 & & & 2 & 7 \\
\hline$S_{2}$ & 70 & 30 & 40 & 60 & 9 \\
\hline$S_{3}$ & & 2 & 7 & & 9 \\
\hline Demand & 5 & 8 & 70 & 20 & 18 \\
\hline
\end{tabular}

Thus, the current basic feasible solution is optimal with minimum total transportation cost Rs 743 [6].

SOLUTION: Here, $n=3$, i.e. In Example, three transportation companies [A, B, C] are jointly apply for transporting a product. So the individual maximum and minimum capacity of transporting units for all parties are as follows:

Table 5

\begin{tabular}{|c|c|c|}
\hline Three parties & $\begin{array}{c}\text { Minimum } \\
\text { capacity for } \\
\text { transporting } \\
\text { units }\end{array}$ & $\begin{array}{c}\text { Maximum } \\
\text { capacity for } \\
\text { transporting } \\
\text { units }\end{array}$ \\
\hline A & 9 & 12 \\
\hline B & 7 & 11 \\
\hline C & 10 & 25 \\
\hline
\end{tabular}

\section{Method 1 Classical Method}

Step 1 Here, $n=3$, i.e. In Example, three transportation companies $B_{1}, B_{2}$ and $B_{3}$ are jointly apply for transporting a product and maximum and minimum capacity for transporting number of units consider by companies $B_{1}, B_{2}$ and $B_{3}$ are $9,7,10$ and 12,11, 25 respectively. Profit matrices for all parties are as follows:

$$
P_{1}=\left[\begin{array}{llll}
7 & 0 & 0 & 5 \\
0 & 6 & 3 & 0 \\
0 & 8 & 0 & 6
\end{array}\right] P_{2}=\left[\begin{array}{llll}
4 & 0 & 0 & 9 \\
0 & 8 & 5 & 0 \\
0 & 6 & 0 & 2
\end{array}\right] P_{3}=\left[\begin{array}{llll}
7 & 0 & 0 & 9 \\
0 & 8 & 5 & 0 \\
0 & 1 & 0 & 6
\end{array}\right]
$$

Step 2 From the profit matrices, obtain the cost matrices for each party are as follows:

$P_{1}^{\prime}=\left[\begin{array}{llll}1 & 0 & 0 & 3 \\ 0 & 2 & 5 & 0 \\ 0 & 0 & 0 & 2\end{array}\right] \quad P_{2}^{\prime}=\left[\begin{array}{llll}5 & 0 & 0 & 0 \\ 0 & 1 & 4 & 0 \\ 0 & 3 & 0 & 7\end{array}\right] \quad P_{3}^{\prime}=\left[\begin{array}{llll}2 & 0 & 0 & 0 \\ 0 & 1 & 4 & 0 \\ 0 & 8 & 0 & 3\end{array}\right]$

Step 3 The problem is solved by considering each time only one party's cost matrix and ignoring the others. The solution sets are obtained as 
$Z_{1}=3, x_{111}=3, x_{321}=6$

$Z_{2}=11, x_{142}=2, x_{222}=2, x_{322}=3$

$Z_{3}=15, x_{113}=5, x_{143}=2, x_{223}=2, x_{343}=1$

$Z_{1}=3, Z_{1}=10$ (for $Z_{2}$ solution set),$Z_{1}=17$ (for $Z_{3}$ solution set)

$Z_{2}=11, Z_{2}=33$ (for $Z_{1}$ solution set), $Z_{2}=34$ (for $Z_{3}$ solution set)

$Z_{3}=15, Z_{3}=54$ (for $Z_{1}$ solution set $), Z_{3}=26$ (for $Z_{2}$ solution set)

\section{Step 4}

Table 6 Pay-off Matrix

\begin{tabular}{|c|c|c|}
\hline$Z_{1}$ & $Z_{2}$ & $Z_{3}$ \\
\hline 3 & 33 & 54 \\
\hline 10 & 11 & 26 \\
\hline 17 & 34 & 15 \\
\hline
\end{tabular}

$L^{1}=3, U^{1}=17, L^{2}=11, U^{2}=34, L^{3}=15, U^{3}=54$

for $k=1, f_{k}^{U}=17, f_{k}^{L}=3, f_{k}^{U}-f_{k}^{L}=14$

for $k=2, f_{k}^{U}=34, f_{k}^{L}=11, f_{k}^{U}-f_{k}^{L}=23$

for $k=3, f_{k}^{U}=54, f_{k}^{L}=15, f_{k}^{U}-f_{k}^{L}=39$

Step 5 (1) Linear Membership Function Substituting the values obtained in Step 3 in Model 2 the following solutions were obtained using LINGO package

$\lambda=0.460526, x_{111}=1.447368, x_{321}=6, x_{341}=4.552632$,

$x_{142}=2, x_{222}=2, x_{232}=5.351974, x_{113}=3.552632$,

$x_{233}=1.648026, x_{343}=7.447368$

Table 7

\begin{tabular}{|c|c|c|c|}
\hline & $Z_{1}$ & $Z_{2}$ & $Z_{3}$ \\
\hline COST & 166.5526 & 294.079 & 282.3684 \\
\hline PROFIT & 85.44737 & 60.75987 & 77.79276 \\
\hline
\end{tabular}

(2) Exponential Membership Function: substituting the values obtained in Step 3 in Model 3 the following solutions were obtained using LINGO package

Table 8

\begin{tabular}{|c|c|c|c|c|c|}
\hline & $\lambda$ & $\mathrm{S}$ & $Z_{1}$ & $Z_{2}$ & $Z_{3}$ \\
\hline Cost & 0.448123 & 0.1 & 166.55 & 269.61 & 306.84 \\
\cline { 2 - 6 } & 0.3991415 & 0.5 & 166.55 & 269.89 & 306.56 \\
\cline { 2 - 6 } & 0.3404039 & 1 & 166.55 & 294.08 & 282.37 \\
\cline { 2 - 6 } & 0.2366442 & 2 & 166.55 & 274.48 & 301.97 \\
\hline Profit & 0.448123 & 0.1 & 85.4474 & 52.5006 & 45.6062 \\
\cline { 2 - 6 } & 0.3991415 & 0.5 & 85.4474 & 52.595 & 85.9577 \\
\cline { 2 - 6 } & 0.3404039 & 1 & 85.4474 & 60.7599 & 77.7928 \\
\cline { 2 - 6 } & 0.2366442 & 2 & 85.4474 & 43.1176 & 95.435 \\
\hline
\end{tabular}

\section{METHOD 2 NASH BARGAINING THEORY BASED SOLUTION}

Now, in Table- 4 of example, there are 6 jobs. Let three transportation companies are jointly for tendering and suppose getting the assignment.
First of all find all possible allocations of every unit of jobs between possible pairs of three transportation companies which are as follows:

Table 9

\begin{tabular}{|c|c|c|c|c|c|c|c|c|c|c|c|c|c|}
\hline \multirow[t]{2}{*}{$J_{1}$} & $\mathrm{Gl}$ & 0 & 1 & 2 & 3 & 4 & 5 & & & & & & \\
\hline & G2 & 5 & 4 & 3 & 2 & 1 & 0 & & & & & & \\
\hline \multirow{2}{*}{$J_{2}$} & G1 & 0 & 1 & 2 & & & & & & & & & \\
\hline & G2 & 2 & 1 & 0 & & & & & & & & & \\
\hline \multirow[t]{2}{*}{$J_{3}$} & G1 & 0 & 1 & 2 & & & & & & & & & \\
\hline & G2 & 2 & 1 & 0 & & & & & & & & & \\
\hline \multirow[t]{2}{*}{$J_{4}$} & $\mathrm{Gl}$ & 0 & 1 & 2 & 3 & 4 & 5 & 6 & 7 & & & & \\
\hline & G2 & 7 & 6 & 5 & 4 & 5 & 2 & & ) & & & & \\
\hline \multirow[t]{2}{*}{$J_{5}$} & G1 & 0 & 1 & 2 & 3 & 4 & 5 & 6 & & & & & \\
\hline & G2 & 6 & 5 & 4 & 3 & 2 & 1 & 0 & & & & & \\
\hline \multirow[t]{2}{*}{$J_{6}$} & G1 & 0 & 1 & 2 & 3 & 4 & 5 & 6 & & 9 & 10 & 11 & 12 \\
\hline & G2 & 12 & 11 & 10 & 9 & 8 & 7 & 6 & 5 & 3 & 2 & 1 & 0 \\
\hline
\end{tabular}

Profit matrices for all parties are given above as $P_{1}, P_{2}$ and $P_{3}$ and solve each party's profit matrix using LINGO package by considering the minimum and maximum capacity of transporting a number of units from origin to destination.

From the minimum and maximum capacity for transporting units as in Table 5, we achieve minimum and maximum transportation profit for all companies A, B and C as 31, 14, 26 and 89, 75, 161 respectively. Apply the above algorithm of $n$-parties bargaining model in example to obtain the optimal solution for three transportation companies which are given below:

\section{Solution using Nash Bargaining Theory based Approach}

Step 1 Three companies can be divided into three possible pairs of group which are as follows:

1) $[\mathrm{A}, \mathrm{B}],[\mathrm{C}]$ 2) $[\mathrm{A}, \mathrm{C}],[\mathrm{B}]$ 3) $[\mathrm{B}, \mathrm{C}],[\mathrm{A}]$ Now all possible strategies of group $[\mathrm{A}, \mathrm{B}]$ and $[\mathrm{C}]$ are 16771 when a minimum and maximum capacity of profit for transporting units are 45, 26 and 164, 161 respectively, and after that apply the minimum and maximum capacity for transporting number of units we achieve possible strategies for group [A, B] and $[C]$ are 2517 which are given in Table 10.

Also, all possible strategies of group [A, C] and $[\mathrm{B}]$ are 13900 when a minimum and maximum capacity of profit for transporting units are 57, 14 and 250, 75 respectively, and after that apply the minimum and maximum capacity for transporting number of units we achieve possible strategies for group $[\mathrm{A}, \mathrm{C}]$ and $[\mathrm{B}]$ are 533 .

All possible strategies of group [B, C] and [A] are 12355 when a minimum and maximum capacity of profit for transporting units are 40, 31 and 236, 89 Respectively and after that apply the 
minimum and maximum capacity for transporting number of units we achieve possible strategies for group [B, C] and [A] are 2517.

Step 2
By Applying the Nash model, the best possible strategy of group [A, B] and [C] for optimal solution at maximization point 20172 , which is given in Table 11 .

Table 10

\begin{tabular}{|c|c|c|c|c|c|c|c|c|c|c|c|c|c|c|c|}
\hline \multicolumn{9}{|c|}{} & $\begin{array}{c}\text { Utilities } \\
\text { of } \\
\text { ofofit } \\
\left(u_{1}\right)\end{array}$ & \multicolumn{9}{|c|}{ Company C } & $\begin{array}{c}\text { Utilities } \\
\text { of } \\
\text { profit } \\
\left(v_{1}\right)\end{array}$ & $\begin{array}{c}\text { Maximization } \\
\text { Points }\end{array}$ \\
\hline 0 & 0 & 0 & 0 & 4 & 12 & 152 & 5 & 2 & 2 & 7 & 2 & 0 & 106 & 16112 \\
\hline 0 & 0 & 0 & 0 & 5 & 11 & 158 & 5 & 2 & 2 & 7 & 1 & 1 & 111 & 17538 \\
\hline 0 & 0 & 0 & 0 & 6 & 10 & 164 & 5 & 2 & 2 & 7 & 0 & 2 & 116 & 19024 \\
\hline 0 & 0 & 0 & 1 & 3 & 12 & 146 & 5 & 2 & 2 & 6 & 3 & 0 & 102 & 14892 \\
\hline 0 & 0 & 0 & 1 & 4 & 11 & 152 & 5 & 2 & 2 & 6 & 2 & 1 & 107 & 16264 \\
\hline$\vdots$ & $\vdots$ & $\vdots$ & $\vdots$ & $\vdots$ & $\vdots$ & $\vdots$ & $\vdots$ & $\vdots$ & $\vdots$ & $\vdots$ & $\vdots$ & $\vdots$ & $\vdots$ & $\vdots$ \\
\hline
\end{tabular}

Table 11

\begin{tabular}{|c|c|c|c|c|c|c|c|c|c|c|c|c|c|c|}
\hline & & ou & A, & & & $\begin{array}{c}\text { Utilities } \\
\text { of } \\
\text { profit }\end{array}$ & & & om & ny & & & $\begin{array}{c}\text { Utilities } \\
\text { of } \\
\text { profit }\end{array}$ & $\begin{array}{c}\text { Maximization } \\
\text { Points }\end{array}$ \\
\hline 0 & 0 & 0 & 7 & 6 & 3 & 164 & 5 & 2 & 2 & 0 & 0 & 9 & 123 & 20172 \\
\hline
\end{tabular}

Thus, group [A, B] achieve profit 164 and Company $\mathrm{C}$ achieves profit 123 at maximization point 20172. Again from the Nash model, best strategy of group [A, C] and [B] for optimal solution at maximization point 17220 and from that group [A, C] achieves profit 246 and Company B achieves profit 70 at maximization point 17220 . Similarly, using the Nash model, best strategy of group [B, C] and $[\mathrm{A}]$ for optimal solution at maximization point 20210. So group [B, C] achieve profit 235 and Company A achieves cost 86 at maximization point 20210.

Step 3

Now, in each group, $[\mathrm{A}, \mathrm{B}],[\mathrm{A}, \mathrm{C}]$ and $[\mathrm{B}$, $\mathrm{C}]$ subgroups are again bargain on each best strategy with respect to their threat points and maximum ability. In subgroup [A, B], all new possible strategies for both companies A and B are 146 when minimum and maximum capacity of profit are 31,14 and 89,75 respectively, and after that apply the minimum and maximum capacity for transporting a number of units, we achieve possible strategies for group [A, B] and [C] are 77 .

Again, in the subgroup $[\mathrm{A}, \mathrm{C}]$, all new possible strategies for both companies $\mathrm{A}$ and $\mathrm{C}$ are 675 when minimum and maximum capacity of profit are 31, 26 and 89, 161 respectively, and after that apply the minimum and maximum capacity for transporting number of units, we achieve possible strategies for group [A, C] and [B] are 283 .
Similarly, in subgroup $[\mathrm{B}, \mathrm{C}]$, all new possible strategies for both companies $\mathrm{B}$ and $\mathrm{C}$ are 2414 when minimum and maximum capacity of profit are 14, 26 and 75, 161 respectively, and after that apply the minimum and maximum capacity for transporting number of units, we achieve possible strategies for group [B, C] and [A] are 1095 .

\section{Step 4}

If Nash model utilize once again, then it will give best strategy for company $\mathrm{A}$ and $\mathrm{B}$ at maximization point 2310. Thus company A obtain profit 66, company B obtains profit 35 at maximization point 2310 and company $\mathrm{C}$ obtain the profit 123. Again from the Nash model, a new possible strategy which is obtained from best strategies gives maximization point 4690 for company A and C. Thus company A obtain profit 70 and company $\mathrm{C}$ obtain profit 67 at maximization point 4690 and company B obtains the profit 70 . If again model utilizes the Nash formula, best strategy for company $\mathrm{B}$ and $\mathrm{C}$ at maximization point 4761 . Thus company B obtains profit 69, company C obtain profit 69 and company A obtain profit 86 .

\section{Step 5}

The maximization points of all three possible groups are as follows:

1. $[[\mathrm{A}, \mathrm{B}]$ and $[\mathrm{C}]]$ is $2,84,130$ for $(\mathrm{A}, \mathrm{B}, \mathrm{C})=(66$, 35,123 ) 
2. $[[\mathrm{A}, \mathrm{C}]$ and $[\mathrm{B}]]$ is $3,28,300$ for $(\mathrm{A}, \mathrm{B}, \mathrm{C})=(70$, 70,67)

3. $[[\mathrm{B}, \mathrm{C}]$ and $[\mathrm{A}]]$ is $4,09,446$ for $(\mathrm{A}, \mathrm{B}, \mathrm{C})=(86$, $69,69)$

Step 6

Here, maximization point of group $[[\mathrm{B}, \mathrm{C}]$ and $[\mathrm{A}]]$ is greatest which gives an optimal solution to each company. Thus, three transportation companies A, B and $\mathrm{C}$ achieve their profit 86,69 and 69 respectively.

\subsection{Transportation Problem With Multiple Objectives}

EXAMPLE 1 A company has four production facilities $T_{1}, T_{2}, T_{3}$ and $T_{4}$ with a production capacity of 5, 4, 2 and 9 units of a product, respectively. These units are to be shipped to five warehouses $D_{1}, D_{2}, D_{3}, D_{4}$ and $D_{5}$ with a requirement of $4,4,6,2$ and 4 units, respectively. The transportation costs, transportation time and product defectiveness between companies to warehouses are given below [4]

$U^{(1)}=\left[\begin{array}{lllll}9 & 12 & 9 & 6 & 9 \\ 7 & 3 & 7 & 7 & 5 \\ 6 & 5 & 9 & 11 & 3 \\ 6 & 8 & 11 & 2 & 2\end{array}\right] U^{(2)}=\left[\begin{array}{lllll}2 & 9 & 8 & 1 & 4 \\ 1 & 9 & 9 & 5 & 2 \\ 8 & 1 & 8 & 4 & 5 \\ 2 & 8 & 6 & 9 & 8\end{array}\right] U^{(3)}=\left[\begin{array}{lllll}2 & 4 & 6 & 3 & 6 \\ 4 & 8 & 4 & 9 & 2 \\ 5 & 3 & 5 & 3 & 6 \\ 6 & 9 & 6 & 3 & 1\end{array}\right]$

Using grey situation decision making theory, convert multi objective transportation problem into the transportation problem with single objective which is given as below:

$$
R=\left[r_{i j}\right]=\left[\begin{array}{lllll}
0.49113 & 0.88188 & 0.86548 & 0.01276 & 0.75148 \\
0.01386 & 0.87603 & 0.87967 & 0.79864 & 0.50123 \\
0.86663 & 0.00493 & 0.86596 & 0.74062 & 0.79469 \\
0.50659 & 0.87365 & 0.67081 & 0.87489 & 0.73053
\end{array}\right]
$$

Solution points of the above matrix using LINGO package are

$x_{12}=2, x_{14}=2, x_{15}=1, x_{21}=4, x_{32}=2, x_{43}=6, x_{45}=3$

SOLUTION: Here, $n=3$, i.e. In Example, three transportation companies $[\mathrm{A}, \mathrm{B}, \mathrm{C}]$ are jointly apply for transporting a product.

So the individual maximum and minimum capacity of transporting units for all parties are as follows:
Table 12

\begin{tabular}{|c|c|c|}
\hline Three parties & $\begin{array}{c}\text { Minimum } \\
\text { capacity for } \\
\text { transporting } \\
\text { units }\end{array}$ & $\begin{array}{c}\text { Maximum } \\
\text { capacity for } \\
\text { transporting } \\
\text { units }\end{array}$ \\
\hline A & 7 & 11 \\
\hline B & 6 & 10 \\
\hline C & 7 & 13 \\
\hline
\end{tabular}

\section{METHOD 1 CLASSICAL METHOD}

Step 1 Here, $n=3$, i.e. In Example, three transportation companies $B_{1}, B_{2}$ and $B_{3}$ are jointly apply for transporting a product and maximum and minimum capacity for transporting number of units consider by companies $B_{1}, B_{2}$ and $B_{3}$ are $7,6,7$ and 11, 10, 13 respectively. Profit matrices for all parties are as follows:

$P_{1}=\left[\begin{array}{lllll}0 & 7 & 0 & 5 & 2 \\ 6 & 0 & 0 & 0 & 0 \\ 0 & 3 & 0 & 0 & 0 \\ 0 & 0 & 8 & 0 & 6\end{array}\right] \quad P_{2}=\left[\begin{array}{lllll}0 & 4 & 0 & 9 & 3 \\ 8 & 0 & 0 & 0 & 0 \\ 0 & 5 & 0 & 0 & 0 \\ 0 & 0 & 6 & 0 & 2\end{array}\right] \quad P_{3}=\left[\begin{array}{lllll}0 & 7 & 0 & 9 & 4 \\ 8 & 0 & 0 & 0 & 0 \\ 0 & 5 & 0 & 0 & 0 \\ 0 & 0 & 1 & 0 & 6\end{array}\right]$

Step 2 From the profit matrices, obtain the cost matrices for each party are as follows:

$P_{1}^{\prime}=\left[\begin{array}{lllll}0 & 1 & 0 & 3 & 6 \\ 2 & 0 & 0 & 0 & 0 \\ 0 & 5 & 0 & 0 & 0 \\ 0 & 0 & 0 & 0 & 2\end{array}\right] \quad P_{2}^{\prime}=\left[\begin{array}{lllll}0 & 5 & 0 & 0 & 6 \\ 1 & 0 & 0 & 0 & 0 \\ 0 & 4 & 0 & 0 & 0 \\ 0 & 0 & 3 & 0 & 7\end{array}\right] \quad P_{3}^{\prime}=\left[\begin{array}{lllll}0 & 2 & 0 & 0 & 5 \\ 1 & 0 & 0 & 0 & 0 \\ 0 & 4 & 0 & 0 & 0 \\ 0 & 0 & 8 & 0 & 3\end{array}\right]$

Step 3 The problem is solved by considering each time only one party's cost matrix and ignoring the others. The solution sets are obtained as

$Z_{1}=1, x_{121}=1, x_{431}=6$

$Z_{2}=4, x_{142}=2, x_{22}=4$

$Z_{3}=6, x_{123}=1, x_{143}=2, x_{213}=4$

$Z_{1}=1, \quad Z_{1}=14\left(\right.$ for $Z_{2}$ solution set $), Z_{1}=15$ (for $Z_{3}$ solution set $)$

$Z_{2}=4, Z_{2}=23$ (for $Z_{1}$ solution set), $Z_{2}=9$ (for $Z_{3}$ solution set)

$Z_{3}=6, Z_{3}=50$ (for $Z_{1}$ solution set $), Z_{3}=4$ (for $Z_{2}$ solution set $)$

\section{Step 4}

Table 13 Pay-off Matrix

\begin{tabular}{|c|c|c|}
\hline$Z_{1}$ & $Z_{2}$ & $Z_{3}$ \\
\hline 1 & 23 & 50 \\
\hline 14 & 4 & 4 \\
\hline 15 & 9 & 6 \\
\hline
\end{tabular}

$$
\begin{aligned}
& L^{1}=1, U^{1}=15, L^{2}=4, U^{2}=23, L^{3}=4, U^{3}=50 \\
& \text { for } k=1, f_{k}^{U}=15, f_{k}^{L}=1, f_{k}^{U}-f_{k}^{L}=14 \\
& \text { for } k=2, f_{k}^{U}=23, f_{k}^{L}=4, f_{k}^{U}-f_{k}^{L}=19 \\
& \text { for } k=3, f_{k}^{U}=50, f_{k}^{L}=4, f_{k}^{U}-f_{k}^{L}=46
\end{aligned}
$$


Step 5 (1) Linear Membership Function Substituting the values obtained in Step 3 in Model 2 the following solutions were obtained using LINGO package

$$
\begin{aligned}
& \lambda=0.7291667, x_{151}=0.6979, x_{431}=6, x_{451}=0.3021, \\
& x_{142}=0.7135, x_{212}=4, x_{322}=1.2865, x_{123}=2, \\
& x_{143}=1.2865, x_{153}=0.3021, x_{323}=0.7135, x_{453}=2.6979
\end{aligned}
$$

Table 14

\begin{tabular}{|c|c|c|c|}
\hline & $Z_{1}$ & $Z_{2}$ & $Z_{3}$ \\
\hline OBJECTIVE 1 & 72.885 & 38.714 & 43.401 \\
\hline OBJECTIVE 2 & 41.208 & 6 & 42.792 \\
\hline OBJECTIVE 3 & 40.49 & 22 & 18.51 \\
\hline PROFIT & 51.208 & 44.854 & 46.542 \\
\hline
\end{tabular}

(2) Exponential Membership Function: substituting the values obtained in Step 3 in Model 3 the following solutions were obtained using LINGO package.

Table 15

\begin{tabular}{|c|c|c|c|c|c|c|}
\hline & $\lambda$ & $\mathrm{S}$ & Obj1 & Obj2 & Obj 3 & Profit \\
\hline \multirow{4}{*}{$Z_{1}$} & 0.7192188 & 0.1 & 72.885 & 41.208 & 40.49 & 51.208 \\
\cline { 2 - 7 } & 0.6781247 & 0.5 & 72.885 & 41.208 & 40.49 & 51.208 \\
\cline { 2 - 7 } & 0.6246659 & 1 & 72.885 & 41.208 & 40.49 & 51.208 \\
\cline { 2 - 7 } & 0.5163187 & 2 & 72.885 & 41.208 & 40.49 & 51.208 \\
\hline \multirow{4}{*}{$Z_{2}$} & 0.7192188 & 0.1 & 36.569 & 6 & 20.285 & 44.854 \\
\cline { 2 - 7 } & 0.6781247 & 0.5 & 39.286 & 6 & 22 & 44.854 \\
\cline { 2 - 7 } & 0.6246659 & 1 & 39.286 & 6 & 22 & 44.854 \\
\cline { 2 - 7 } & 0.5163187 & 2 & 39.286 & 6 & 22 & 44.854 \\
\hline \multirow{4}{*}{$Z_{3}$} & 0.7192188 & 0.1 & 45.545 & 42.792 & 20.226 & 46.542 \\
\cline { 2 - 7 } & 0.6781247 & 0.5 & 43.401 & 42.792 & 18.51 & 46.542 \\
\cline { 2 - 7 } & 0.6246659 & 1 & 43.401 & 42.792 & 18.51 & 46.542 \\
\cline { 2 - 7 } & 0.5163187 & 2 & 43.401 & 42.792 & 18.51 & 46.542 \\
\hline
\end{tabular}

\section{METHOD 2 NASH BARGAINING THEORY BASED METHOD}

Profit matrices for all parties are given above as $P_{1}, P_{2}$ and $P_{3}$ and solve each party's profit matrix using LINGO package by considering the minimum and maximum capacity of transporting a number of units from origin to destination. From the minimum and maximum capacity for transporting units, we achieve minimum and maximum transportation profit for all companies A, B and C as 30, 17, 10 and 80, 74, 92 respectively. Apply the above algorithm of $n$-parties bargaining model in example to obtain the optimal solution for three transportation companies which are given below:

\section{Solution using Nash Bargaining Theory based Approach}

Step 1 Three companies can be divided into three possible pairs of group which are as follows:

1) $[\mathrm{A}, \mathrm{B}],[\mathrm{C}]$ 2) $[\mathrm{A}, \mathrm{C}],[\mathrm{B}]$ 3) $[\mathrm{B}, \mathrm{C}],[\mathrm{A}]$ Now all possible strategies of group $[\mathrm{A}, \mathrm{B}]$ and $[\mathrm{C}]$ are 5900 when a minimum and maximum capacity of profit for transporting units are 47, 10 and 154, 92 respectively, and after that apply the minimum and maximum capacity for transporting number of units we achieve possible strategies for group [A, B] and $[C]$ are 300 which are given in Table 16.

Also all possible strategies of group [A, C] and [B] are 5870 when a minimum and maximum capacity of profit for transporting units are 40, 17 and 172, 74 respectively, and after that apply the minimum and maximum capacity for transporting number of units we achieve possible strategies for group [A, C] and [B] are 690 .

All possible strategies of group [B, C] and [A] are 5576 when a minimum and maximum capacity of profit for transporting units are 27, 30 and 166, 80 Respectively and after that apply the minimum and maximum capacity for transporting number of units we achieve possible strategies for group [B, C] and [A] are 1071 .

\section{Step 2}

By Applying the Nash model, the best possible strategy of the group [A, B] and [C] for optimal solution at maximization point 8056 , which is given in Table 17.

Table 16

\begin{tabular}{|c|c|c|c|c|c|c|c|c|c|c|c|c|c|c|c|c|}
\hline \multicolumn{10}{|c|}{} & $\begin{array}{c}\text { Utilities } \\
\text { of } \\
\text { profit } \\
\left(u_{1}\right)\end{array}$ & \multicolumn{10}{|c|}{$\begin{array}{c}\text { Company C } \\
\text { Utilities } \\
\text { of } \\
\text { profit } \\
\left(v_{1}\right)\end{array}$} & $\begin{array}{c}\text { Maximization } \\
\text { Points }\end{array}$ \\
\hline 0 & 0 & 0 & 0 & 0 & 2 & 3 & 52 & 2 & 2 & 1 & 4 & 2 & 4 & 0 & 15 & 4264 \\
\hline 0 & 0 & 0 & 0 & 0 & 3 & 2 & 58 & 2 & 2 & 1 & 4 & 2 & 3 & 1 & 15 & 5046 \\
\hline 0 & 0 & 0 & 0 & 0 & 3 & 3 & 66 & 2 & 2 & 1 & 4 & 2 & 3 & 0 & 14 & 5346 \\
\hline 0 & 0 & 0 & 0 & 0 & 4 & 1 & 64 & 2 & 2 & 1 & 4 & 2 & 2 & 2 & 15 & 5888 \\
\hline 0 & 0 & 0 & 0 & 0 & 4 & 2 & 72 & 2 & 2 & 1 & 4 & 2 & 2 & 1 & 14 & 6192 \\
\hline$\vdots$ & $\vdots$ & $\vdots$ & $\vdots$ & $\vdots$ & $\vdots$ & $\vdots$ & $\vdots$ & $\vdots$ & $\vdots$ & $\vdots$ & $\vdots$ & $\vdots$ & $\vdots$ & $\vdots$ & $\vdots$ & $\vdots$ \\
\hline
\end{tabular}


Table 17

\begin{tabular}{|c|c|c|c|c|c|c|c|c|c|c|c|c|c|c|c|c|}
\hline & & & $\mathrm{p}$ [ & , B & & & $\begin{array}{l}\text { Utiliti } \\
\text { es of } \\
\text { profit }\end{array}$ & & & $\mathrm{Co}$ & par & & & & $\begin{array}{l}\text { Utiliti } \\
\text { es of } \\
\text { profit }\end{array}$ & $\begin{array}{c}\text { Maximization } \\
\text { Points }\end{array}$ \\
\hline 1 & 0 & 1 & 2 & 2 & 6 & 1 & 152 & 1 & 2 & 0 & 2 & 0 & 0 & 2 & 53 & 8056 \\
\hline
\end{tabular}

Thus, group [A, B] achieve profit 152 and Company $\mathrm{C}$ achieves profit 53 at maximization point 8056. Again from the Nash model, best strategy of group $[\mathrm{A}, \mathrm{C}]$ and $[\mathrm{B}]$ for optimal solution at maximization point 7000 and from that group $[\mathrm{A}, \mathrm{C}]$ achieve profit 140 and Company B achieves profit 50 at maximization point 7000. Similarly, using the Nash model, best strategy of group [B, C] and [A] for optimal solution at maximization point 8910 . So group $[\mathrm{B}, \mathrm{C}]$ achieves profit 165 and Company A achieves profit 54 at maximization point 8910 .

\section{Step 3}

Now, in each group, $[\mathrm{A}, \mathrm{B}],[\mathrm{A}, \mathrm{C}]$ and $[\mathrm{B}$, C] subgroups are again bargain on each best strategy with respect to their threat points and maximum ability. In subgroup [A, B], all new possible strategies for both companies A and B are 298 when minimum and maximum capacity of profit are 30,17 and 80, 74 respectively, and after that apply the minimum and maximum capacity for transporting a number of units, we achieve possible strategies for group A and B are 199.

Again, in the subgroup [A, C], all new possible strategies for both companies $\mathrm{A}$ and $\mathrm{C}$ are 355 when a minimum and maximum capacity of profit are 30, 10 and 80, 92 respectively and after that apply the minimum and maximum capacity for transporting number of units, we achieve possible strategies for company A and $\mathrm{C}$ are 70 .

Similarly, in subgroup $[\mathrm{B}, \mathrm{C}]$, all new possible strategies for both companies $\mathrm{B}$ and $\mathrm{C}$ are 321 when the minimum and maximum capacity of profit are 17, 10 and 74, 92 respectively and after that apply the minimum and maximum capacity for transporting number of units, we achieve possible strategies for company B and C are 68.

\section{Step 4}

If Nash model utilize once again, then it will give best strategy for company $\mathrm{A}$ and $\mathrm{B}$ at maximization point 1855 . Thus company A obtain profit 53, company B obtains profit 35 at maximization point 1855 and company $\mathrm{C}$ obtains the profit 53. Again from the Nash model, a new possible strategy which is obtained from best strategies gives maximization point 2160 for company A and C.
Thus company A obtain profit 54 and company $\mathrm{C}$ obtain profit 40 at maximization point 2160 and company B obtains the profit 50. If again model utilizes the Nash formula, best strategy for company $\mathrm{B}$ and $\mathrm{C}$ at maximization point 3182 . Thus company B obtains profit 74 , company $\mathrm{C}$ obtain profit 43 and company A obtain profit 54.

\section{Step 5}

The maximization points of all three possible groups are as follows:

1. $[[\mathrm{A}, \mathrm{B}]$ and $[\mathrm{C}]]$ is 98,315 for $(\mathrm{A}, \mathrm{B}, \mathrm{C})=(53$, $35,53)$

2. $[[\mathrm{B}, \mathrm{C}]$ and $[\mathrm{A}]]$ is $1,71,828$ for $(\mathrm{A}, \mathrm{B}, \mathrm{C})=(54$, 74, 43)

3. $[[\mathrm{A}, \mathrm{C}]$ and $[\mathrm{B}]]$ is $1,08,000$ for $(\mathrm{A}, \mathrm{B}, \mathrm{C})=(54$, $50,40)$

\section{Step 6}

Here, maximization point of group $[[\mathrm{B}, \mathrm{C}]$ and $[\mathrm{A}]]$ is greatest which gives an optimal solution to each company. Thus, three transportation companies A, B and $\mathrm{C}$ achieve their profit 54, 74 and 43 respectively.

\section{CONCLUSION}

This paper gives the integer and non integer solutions using classical method and bargaining theory based approach for all companies when numbers of companies are joining together in tendering process according to their capacity for transporting units. So when such type of situation occurs in real life, both methods give more preferable solutions for all companies.

\section{REFERENCES}

[1] Abhiay Muthoo, A Non-Technical Introduction to Bargaining Theory, World Economics. Vol. 1, No. 2, 2000, 145-166.

[2] Alfred Asase, The Transportation Problem, Case Study, Guiness Ghana Limited, Faculty of Physical Science and Technology, Kumasi, 2011.

[3] Arindam Chaudhuri, Dr. Kajal De, A Comparative study of the Transportation Problem under Probabilistic and Fuzzy Uncertainties, Journal of Bangladesh Mathematical Society, Dhaka, Bangladesh, 2009. 
[4] Deepika Rani, Fuzzy Programming Technique for Solving Different Types of Multi-objective Transportation Problem School of Mathematics and Computer, Thapar University, Punjab, 2010.

[5] Guozhong Bai and Lina Yao, A simple algorithm for the multi objective Transportation, Business Management and Electronic Information, IEEE, 2011, 479482.

[6] J. K. Sharma, Operations research theory and applications, (Macmillan India Ltd (second edition), New Delhi, 2003).

[7] John F. Nash, The Bargaining Problem, Econometrica: Journal of the Econometric Society, 18, 1950, 155-162.

[8] Martin J. Osborne and Ariel Rubinstein, Bargaining and Market, (Academic press, New York, 1990).
[9] Mohammad Kamrul Hasan (2012), “Direct Methods for Finding Optimal Solution of a Transportation Problem are not Always Reliable, International Refereed Journal of Engineering and Science (IRJES), 1(2), 2012, 46-52.

[10] P. Judson Kenney, Supply Chain Bargaining Theory, Desautels Faculty of Management, McGill University, Canada, 2013.

[11] S Williamsom, A literature review on bargaining for family friendly working arrangements, Research gate, University of Sydney, 2007.

[12] Ujjwal Kumar, Cyber Haggler: Web Based Bargaining using Genetic Algorithm, Artificial intelligence, computer science, 2007.

[13] Y.H. Gu, A new two-party bargaining mechanism, J Comb optimization, Springer, $25,2013,135-163$. 